\title{
Decomposing Urban-rural Differences in Multimorbidity Among Older Adults in India: A Study Based on Lasi Data
}

\section{Shekhar Chauhan}

International Institute for Population Sciences

\section{Shobhit Srivastava}

International Institute for Population Sciences

Pradeep Kumar

International Institute for Population Sciences

Ratna Patel ( $\nabla$ ratnapatelbhu@gmail.com )

International Institute for Population Sciences

\section{Research Article}

Keywords: Multimorbidity, Urban-rural differences, Obesity, LASI, India

Posted Date: October 4th, 2021

DOI: https://doi.org/10.21203/rs.3.rs-701569/v1

License: (a) (i) This work is licensed under a Creative Commons Attribution 4.0 International License.

Read Full License

Version of Record: A version of this preprint was published at BMC Public Health on March 15th, 2022.

See the published version at https://doi.org/10.1186/s12889-022-12878-7. 
1 Decomposing urban-rural differences in multimorbidity among older adults in India: A

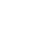 \\ Authors:}

1. Shekhar Chauhan

Affiliation: Ph.D. Research Scholar, Department of Population Policies and Programmes, International Institute for Population Sciences, Mumbai, India

Email: shekhariips2486@gmail.com

\section{Shobhit Srivastava}

Affiliation: Ph.D. Research Scholar, Department of Mathematical Demography \& Statistics, International Institute for Population Sciences, Mumbai, India

Email: shobhitsrivastava889@gmail.com

\section{Pradeep Kumar}

Affiliation: Ph.D. Research Scholar, Department of Mathematical Demography \& Statistics, International Institute for Population Sciences, Mumbai, India

Email: pradeepiips@yahoo.com

\section{Ratna Patel (corresponding)}

Affiliation: Ph.D. Research Scholar, Department of Public Health and Mortality Studies, International Institute for Population Sciences, Mumbai, India

Email: ratnapatelbhu@gmail.com 


\section{Abstract}

Background: Multimorbidity is defined as the co-occurrence of two or more than two diseases in the same person. With rising longevity, multimorbidity has become a prominent concern among the older population. Evidence from both developed and developing countries shows that older people are at much higher risk of multimorbidity, however, urban-rural differential remained scarce. Therefore, this study examines urban-rural differential in multimorbidity among older adults by decomposing the risk factors of multimorbidity and identifying the covariates that contributed to the change in multimorbidity.

Methods: The study utilized information from 31,464 older adults (rural-20,725 and urban10,739) aged 60 years and above from the recent release of the Longitudinal Ageing Study in India (LASI) wave 1 data. Descriptive, bivariate, and multivariate decomposition analysis techniques were used.

Results: Overall, significant urban-rural differences were found in the prevalence of multimorbidity among older adults (difference: 16.3; $\mathrm{p}<0.001$ ). Moreover, obese/overweight and high-risk waist circumference were found to narrow the difference in the prevalence of multimorbidity among older adults between urban and rural areas by $8 \%$ and $9.1 \%$, respectively.

Conclusion: There is a need to substantially increase the public sector investment in healthcare to address the multimorbidity among older adults, more so in urban areas, without compromising the needs of older adults in rural areas. 

study based on LASI data

Background:

Declining fertility rates and increasing life expectancy have increased the population of older adults worldwide [1]. As per the World Population Prospects report, by 2050, 1 in 6 people worldwide would be over 65 years of age, up from 1 in 11 in 2019 [2]. Nearly all the societies in the world are in the midst of this longevity revolution, albeit at a different stage with differing pace [2]. Like other developing countries, India is also in the transition phase, experiencing an increase in the proportion of older adults' population [3]. Considering increasing education and improving health facilities, the share of the older adults' population (60+ years) in India has increased from 5.3 percent in 1971 to 5.7 percent in 1981 and further from 6 percent in 1991 to almost 8 percent in 2011 [4]. Furthermore, it is evident that older adults' proportion in India will continue to increase in the future, however, concerning various health problems [5]. While global ageing depicts a triumph of medical, social, and economic advances over disease, it also represents tremendous challenges [6]. Multimorbidity is one such challenge that becomes very prominent during ageing [7]. Developed as well as developing countries [8]-[11] including India [12], [13] are experiencing a rise in the prevalence of multimorbidity among older adults.

Multimorbidity is defined as the co-occurrence of two or more than two diseases in the same person [14]. With rising longevity, multimorbidity has become a prominent concern among the older population. Evidence from both developed and developing countries shows that older people are at much higher risk of multimorbidity [9], [15]-[17]. Multimorbidity has been associated with several adverse health outcomes among older adults, including reduced physical and cognitive functions [18]-[23], reduced quality of life [24], [25], elevated risk of 
differential) is a significant risk factor in the occurrence of multimorbidity among older adults [26]. This becomes even more poignant and alarming considering the higher prevalence of multimorbidity among older adults urban than their rural counterparts [12].

Several studies have examined the prevalence and determinants of multimorbidity among older adults in developed countries [11], [27], [28]; however, the available literature on multimorbidity in developing countries [9], [29], [30] including India [31] is limited. Moreover, almost all the latest research on multimorbidity among older adults in India is more of community-based, instead depicting the national picture [32]-[37]. To add more to the literature gap, previously available literature significantly proposed various risk factors of multimorbidity among older adults [31], [32], [34], [35], [38]; however, none of the study exclusively examined rural-urban differential in multimorbidity among older adults in India in recent times utilizing information on a nationally representative large scale survey data. A study examined urban-rural differential in multimorbidity among adults in India [26]. Therefore, this study intends to examine rural-urban differential in multimorbidity among older adults by utilizing data from Longitudinal Ageing Survey in India (LASI), 2017-18. Moreover, this study decomposes the risk factors of multimorbidity and identifies the covariates that contributed to the change in multimorbidity by rural and urban residents.

\section{Methods}

\section{Data}

The study carried out data from the first wave of the Longitudinal Ageing Study in India (LASI), conducted in 2017-18 [39]. LASI is a national representative survey which gathered the information of economic, health, and social drivers of population ageing in India [39]. About 72000 older persons in India's states and union territories were surveyed in LASI [39]. The primary objective of the survey was to look into the physical and social and economic 
well-being of older persons in India. To arrive at the final units of observation, LASI used a multistage stratified area probability cluster sampling method [39]. This included older people aged 45 and up, as well as their spouses of any age. The survey used a three-stage sampling in rural areas, whereas in urban areas, it used a four-stage sampling approach [39]. The initial stage in each state/UT was to choose Primary Sampling Units (PSUs), or sub-districts (Tehsils/Talukas). In the selected PSUs, the second stage entails choosing villages in rural regions and wards in urban areas [39]. In the third step, families were chosen from various communities in rural areas. Sampling in urban areas, on the other hand, required an extra step. In the third step, one Census Enumeration Block (CEB) was chosen at random in each urban area [39]. Households from this CEB were chosen in the fourth stage. Detailed about survey design and data collection procedure has been published elsewhere [39]. The present study used data on the eligible respondents age 60 years and above [39]. The total sample size for the present study is 31,464 older adults aged 60 years and above (rural-20,725 and urban-10,739).

\section{Variable description}

\section{Outcome description}

The outcome variable was categorized as binary, i.e., multimorbidity (no/yes) [40]. Multimorbidity is defined as the presence of two or more chronic diseases, such as hypertension, stroke, chronic heart disease, diabetes, neurological/psychiatric disease, cancer or malignant tumour, any bone/joint disease, any chronic lung disease, or high cholesterol [39]. The diseases were self-reported, however, diagnosed [41] as was assessed through the question "Has any health professional ever diagnosed you with the following chronic conditions or diseases?" [40].

\section{Explanatory variables}


127 The place of residence was categorized as rural and urban. However, an earlier multi-country 128 study stated that urban-rural differences in multimorbidity vary from country to country, and it 129 is suggested to undertake country-wise studies examining urban-rural differences in multimorbidity to predict the necessary strategies to address the multimorbidity [42].

131 Therefore, this study intends to examine urban-rural differential in multimorbidity among older 132 adults in India.

\section{Main explanatory variables}

\section{Obesity-related factors}

Overweight/obesity was categorized as no and yes [43]. Obese/overweight was defined as having a body mass index of $\geq 25 \mathrm{~kg} / \mathrm{m}^{2}$. No and yes were used to categorise high-risk waist circumference [43]. High-risk waist circumferences were defined as male and female waist circumferences of greater than $102 \mathrm{~cm}$ and $88 \mathrm{~cm}$, respectively [44]. No and yes were used to categorise high-risk waist-hip ratios. Males and females with waist-hip ratios more than 0.90 $\mathrm{cm}$ and $0.85 \mathrm{~cm}$, respectively, were classified as having a high-risk waist-hip ratio [44].

Behavioural factors

Physical activity levels were classified as frequent (every day), rare (once a week, once a month, one to three times a month), and never [40]. Tobacco and alcohol consumption was recoded as no and yes [40].

\section{Individual factors}

146 Age was recoded as young old (60-69 years), old-old (70-79 years), and oldest-old (80+ years)

147 [45]. Sex was recoded as male and female. Education was categorized as no education/primary schooling not completed, primary completed, secondary completed, and higher and above. 
Marital status was coded as currently married, widowed, and others (separated/never married/divorced) [45]. Finally, working status was recoded as working, retired, and not working [45].

\section{Household factors}

The monthly per capita expenditure (MPCE) quintile was calculated using household consumption data. The sample houses were questioned on food and non-food expenses with sets of 11 and 29 questions, respectively. Non-food expenditure was collected over 30-day and 365-day reference periods, whereas food expenditure was collected over a seven-day reference period. Food and non-food expenses were standardised using a 30-day reference period [39]. As a summary measure of consumption, the monthly per capita consumption expenditure (MPCE) is computed and used. The variable was then divided into five quintiles, i.e., from poorest to richest. Religion was coded as Hindu, Muslim, Christian, and Others. Caste was categorized as Scheduled Tribe (ST), Scheduled Caste (SC), Other Backward Class (OBC), and others. As a result of their low caste status in Hindu society, the Scheduled Caste is a group of people who are socially isolated and financially/economically disadvantaged [40], [46]. The Scheduled Castes and Tribes of India are among the poorest socioeconomic groupings in the country [40], [46]. The OBC is the group of people identified as "educationally, economically and socially backward [40], [46]." The OBCs are considered lower castes in the traditional caste system [40], [46]. The "other" caste category is identified as having higher social status. The geographical region was recoded as North, Central, East, Northeast, West, and South [47].

\section{Statistical approach}

To show the preliminary findings, descriptive analysis and bivariate analysis were used. To analyse the residential differentials and determine the significance level, the proportion test was utilised [48]. In addition, a multivariate decomposition logistic regression analysis was 
used to identify the contributions of covariates which explain the group differences to average predictions [49]. The aim of the decomposition analysis was to identify covariates that contributed to the change in multimorbidity by rural and urban places of residence.

The compositional differences (endowments) ' $E$ ' and the effects of characteristics, which are the differences in the coefficients or behavioural change ' $\mathrm{C}$ ' responses for the selected predictor variables, are the two contributing effects in the multivariate decomposition analysis [50]. As a result, the observed variations in multimorbidity may be decomposed additively into characteristics (or endowments) and a coefficient (or effects of features) component [51]. In the non-linear model, the dependent variable is a function of a linear combination of predictors and regression coefficients:

$Y=F(X \beta)=$ logit $(Y)=X \beta$, where $\mathrm{Y}$ denotes the $\mathrm{n}^{*} 1$ dependent variable vector, $\mathrm{X}$ an $\mathrm{n} * \mathrm{~K}$ matrix of independent variables, and $\beta$ a $\mathrm{K}^{*} 1$ vector of coefficients.

The proportion difference in $\mathrm{Y}$ between urban $\mathrm{A}$ and urban $\mathrm{B}$ of multimorbidity can be decomposed as:

$$
Y_{A}-Y_{B}=F\left(X_{A} \beta_{A}\right)-F\left(X_{B} \beta_{B}\right)
$$

For the log odds of multimorbidity, the proportion of the model is written as

$$
\begin{aligned}
& \operatorname{Logit}\left(Y_{A}\right)-\operatorname{logit}\left(Y_{B}\right)=F\left(X_{A} \beta_{A}\right)-F\left(X_{B} \beta_{B}\right) \\
& =F\left(X_{A} \beta_{A}\right)-F\left(X_{B} \beta_{A}\right)+F\left(X_{B} \beta_{A}\right)-F\left(X_{B} \beta_{B}\right)
\end{aligned}
$$

$$
\text { E C }
$$

The difference due to endowment change is the component 'E,' also known as the explained component. The difference attributed to coefficient (behavioural) change, often known as the unexplained component, is the ' $\mathrm{C}$ ' component.

The model structure for the decomposition analysis was: 
$\operatorname{Logit}(A)-\operatorname{Logit}(B)=\left[\beta_{0 A}-\beta_{0 B}\right]+\sum \beta_{i j A}\left[X_{i j A}-X_{i j B}\right]+\sum X_{i j B}\left[\beta_{i j A}-\beta_{i j B}\right]$, where

- $\beta_{0 A}$ is the intercept in the regression equation for rural

- $\beta_{0 B}$ is the intercept in the regression equation for urban

- $\beta_{i j A}$ is the coefficient of the $j^{\text {th }}$ category of the $i^{\text {th }}$ determinant for rural

- $\beta_{i j B}$ is the coefficient of the $j^{\text {th }}$ category of the $i^{\text {th }}$ determinant for urban

- $X_{i j A}$ is the proportion of the $j^{\text {th }}$ category of the $i^{\text {th }}$ determinant for rural

- $X_{i j B}$ is the proportion of the $j^{\text {th }}$ category of the $i^{\text {th }}$ determinant for urban

The command $m v d c m p$ was used to carry out multivariate decomposition analysis in STATA $14[52]$.

\section{Results:}

\section{Socio-economic profile of study population, 2017-18 (Table 1)}

The prevalence of obesity-related factors such as obese/overweight, high-risk waist circumference, and high-risk waist-hip ratio was higher among urban resident older adults than rural counterparts (see table 1). Moreover, among behavioural factors, rural resident older adults did more frequent physical activity than urban ones (19.2\% vs. $15 \%)$. Similarly, tobacco (45.2\% vs. $26.6 \%)$ and alcohol consumption (15.7\% vs. $11.3 \%)$ was more prevalent among older adults who lived in rural areas than those who lived in urban areas. A higher proportion of older adults belonged to the young-old cohort in both rural and urban areas. The proportion of older adults with no education/primary not completed were higher in rural (77.1\%) areas than urban (46\%). Similarly, the percentage of working older adults was higher in rural areas (35.4\%) than urban $(19.6 \%)$ counterparts.

Table-1. Socio-economic profile of older adults in India, 2017-18

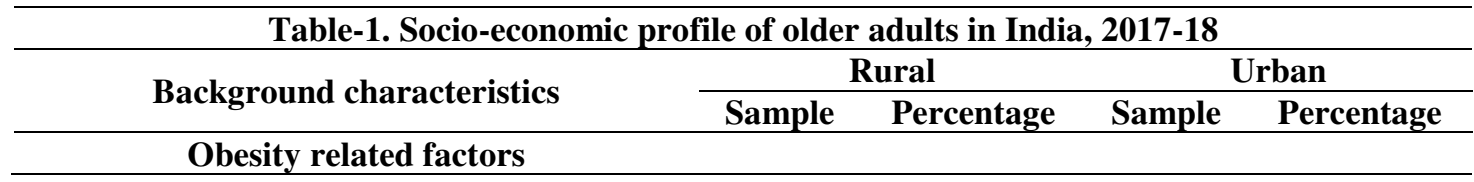




\begin{tabular}{|c|c|c|c|c|}
\hline \multicolumn{5}{|l|}{ Obese/overweight } \\
\hline No & 17,863 & 86.2 & 7,160 & 66.7 \\
\hline Yes & 2,862 & 13.8 & 3,579 & 33.3 \\
\hline \multicolumn{5}{|l|}{ High risk waist circumference } \\
\hline No & 17,536 & 84.6 & 7,069 & 65.8 \\
\hline Yes & 3,189 & 15.4 & 3,670 & 34.2 \\
\hline \multicolumn{5}{|l|}{ High risk waist-hip ratio } \\
\hline No & 6,994 & 33.8 & 3,016 & 28.1 \\
\hline Yes & 13,731 & 66.3 & 7,723 & 71.9 \\
\hline \multicolumn{5}{|l|}{ Behavioural factors } \\
\hline \multicolumn{5}{|l|}{ Physical activity status } \\
\hline Frequent & 3,980 & 19.2 & 1,610 & 15.0 \\
\hline Rare & 3,101 & 15.0 & 813 & 7.6 \\
\hline Never & 13,644 & 65.8 & 8,317 & 77.4 \\
\hline \multicolumn{5}{|l|}{ Tobacco consumption } \\
\hline No & 11,353 & 54.8 & 7,886 & 73.4 \\
\hline Yes & 9,372 & 45.2 & 2,853 & 26.6 \\
\hline \multicolumn{5}{|l|}{ Alcohol consumption } \\
\hline No & 17,465 & 84.3 & 9,523 & 88.7 \\
\hline Yes & 3,260 & 15.7 & 1,216 & 11.3 \\
\hline \multicolumn{5}{|l|}{ Individual factors } \\
\hline \multicolumn{5}{|l|}{ Murviuar hactós } \\
\hline Young-old & 12,139 & 58.6 & 6,268 & 58.4 \\
\hline Old-old & 6,169 & 29.8 & 3,354 & 31.2 \\
\hline Oldest-old & 2,417 & 11.7 & 1,117 & 10.4 \\
\hline \multicolumn{5}{|l|}{ Sex } \\
\hline Male & 10,045 & 48.5 & 4,835 & 45.0 \\
\hline Female & 10,680 & 51.5 & 5,904 & 55.0 \\
\hline \multicolumn{5}{|l|}{ Education } \\
\hline Not educated/primary not completed & 15,986 & 77.1 & 4,937 & 46.0 \\
\hline Primary & 2,069 & 10.0 & 1,511 & 14.1 \\
\hline Secondary & 1,988 & 9.6 & 2,598 & 24.2 \\
\hline Higher & 682 & 3.3 & 1,693 & 15.8 \\
\hline \multicolumn{5}{|l|}{ Marital status } \\
\hline Currently married & 13,017 & 62.8 & 6,315 & 58.8 \\
\hline Widowed & 7,280 & 35.1 & 4,162 & 38.8 \\
\hline Others & 427 & 2.1 & 262 & 2.4 \\
\hline \multicolumn{5}{|l|}{ Working status } \\
\hline Working & 7,341 & 35.4 & 2,106 & 19.6 \\
\hline Retired & 8,774 & 42.3 & 4,719 & 43.9 \\
\hline Not working & 4,610 & 22.2 & 3,913 & 36.4 \\
\hline \multicolumn{5}{|l|}{ Household factors } \\
\hline \multicolumn{5}{|l|}{ MPCE quintile } \\
\hline Poorest & 4,446 & 21.5 & 2,396 & 22.3 \\
\hline Poorer & 4,608 & 22.2 & 2,197 & 20.5 \\
\hline Middle & 4,375 & 21.1 & 2,207 & 20.6 \\
\hline Richer & 3,932 & 19.0 & 2,117 & 19.7 \\
\hline Richest & 3,364 & 16.2 & 1,822 & 17.0 \\
\hline \multicolumn{5}{|l|}{ Religion } \\
\hline Hindu & 17,309 & 83.5 & 8,497 & 79.1 \\
\hline Muslim & 2,021 & 9.8 & 1,604 & 14.9 \\
\hline Christian & 623 & 3.0 & 269 & 2.5 \\
\hline Others & 772 & 3.7 & 369 & 3.4 \\
\hline \multicolumn{5}{|l|}{ Caste } \\
\hline Scheduled Caste & 4,572 & 22.1 & 1,220 & 11.4 \\
\hline Scheduled Tribe & 2,125 & 10.3 & 325 & 3.0 \\
\hline Other Backward Class & 9,213 & 44.5 & 5,056 & 47.1 \\
\hline Others & 4,815 & 23.2 & 4,139 & 38.5 \\
\hline Region & & & & \\
\hline North & 2,655 & 12.8 & 1,293 & 12.0 \\
\hline
\end{tabular}




\begin{tabular}{lcccc} 
Central & 4,920 & 23.7 & 1,533 & 14.3 \\
East & 5,678 & 27.4 & 1,573 & 14.7 \\
Northeast & 691 & 3.3 & 226 & 2.1 \\
West & 2,898 & 14.0 & 2,662 & 24.8 \\
South & 3,883 & 18.7 & 3,451 & 32.1 \\
\hline Total & 20,725 & 100.0 & 10,739 & 100.0 \\
\hline
\end{tabular}

Overall, significant urban-rural differences were found in the prevalence of multimorbidity among older adults (difference: 16.3; $\mathrm{p}<0.001$ ) (see table 2). It was higher in urban areas compared to rural counterparts $(35.4 \%$ vs. $19.1 \%)$. Among the obesity-related factors, a significant higher urban-rural difference in the prevalence of multimorbidity was found among older adults who had a high risk waist-hip ratio (difference: $15.9 \%$; $\mathrm{p}<0.001$ ) followed by those who had high waist circumference (difference: $14.5 \%$; $\mathrm{p}<0.001$ ). Moreover, among behavior factors, higher urban-rural differences were observed among older adults who did physical activity rarely (difference: 19.8\%; $\mathrm{p}<0.001$ ), followed by those who consumed alcohol (difference: $17 \% ; \mathrm{p}<0.001$ ). In the case of individual factors, a significant urban-rural difference was found in the prevalence of multimorbidity among older adults who belonged to other marital status categories followed by those not working. In contrast, this difference was lowest among the oldest-old cohort (difference: $7.3 \%$; $<<0.001$ ), followed by those who had higher education (difference: $9.7 \%$; $\mathrm{p}<0.001$ ). Moreover, a higher percentage of urban-rural difference in the prevalence of multimorbidity was observed among older adults who belonged to the wealthiest families (difference: $24.1 \% \mathrm{p}<0.001$ ).

\begin{tabular}{|c|c|c|c|c|}
\hline \multicolumn{5}{|c|}{ Table-2. Percentage of older adults suffering from multimorbidity in India, 2017-18 } \\
\hline \multirow{2}{*}{ Background characteristics } & Rural & Urban & Differences & p-value \\
\hline & $\%$ & $\%$ & $\%$ & \\
\hline \multicolumn{5}{|l|}{ Obesity related factors } \\
\hline \multicolumn{5}{|l|}{ Obese/overweight } \\
\hline No & 16.3 & 28.8 & 12.5 & 0.001 \\
\hline Yes & 36.6 & 48.6 & 11.9 & 0.001 \\
\hline \multicolumn{5}{|l|}{ High risk waist circumference } \\
\hline No & 16.2 & 28.0 & 11.8 & 0.001 \\
\hline Yes & 35.1 & 49.6 & 14.5 & 0.001 \\
\hline
\end{tabular}

High risk waist-hip ratio 


\begin{tabular}{|c|c|c|c|c|}
\hline No & 15.4 & 31.5 & 16.1 & 0.001 \\
\hline Yes & 21.0 & 36.9 & 15.9 & 0.001 \\
\hline \multicolumn{5}{|l|}{ Behavioural factors } \\
\hline \multicolumn{5}{|l|}{ Physical activity status } \\
\hline Frequent & 13.1 & 29.0 & 15.9 & 0.001 \\
\hline Rare & 12.4 & 32.2 & 19.8 & 0.001 \\
\hline Never & 22.4 & 36.9 & 14.5 & 0.001 \\
\hline \multicolumn{5}{|l|}{ Tobacco consumption } \\
\hline No & 20.8 & 37.4 & 16.6 & 0.001 \\
\hline Yes & 17.1 & 29.9 & 12.8 & 0.001 \\
\hline \multicolumn{5}{|l|}{ Alcohol consumption } \\
\hline No & 19.7 & 35.7 & 16.0 & 0.001 \\
\hline Yes & 15.9 & 32.9 & 17.0 & 0.001 \\
\hline \multicolumn{5}{|l|}{ Individual factors } \\
\hline \multicolumn{5}{|l|}{ Age } \\
\hline Young-old & 17.8 & 34.8 & 17.1 & 0.001 \\
\hline Old-old & 20.4 & 38.3 & 17.9 & 0.001 \\
\hline Oldest-old & 22.6 & 29.8 & 7.3 & 0.012 \\
\hline \multicolumn{5}{|l|}{ Sex } \\
\hline Male & 18.2 & 32.5 & 14.2 & 0.001 \\
\hline Female & 19.9 & 37.8 & 17.9 & 0.001 \\
\hline \multicolumn{5}{|l|}{ Education } \\
\hline Not educated/primary not completed & 17.5 & 28.8 & 11.3 & 0.001 \\
\hline Primary & 23.8 & 40.8 & 17.0 & 0.001 \\
\hline Secondary & 24.0 & 42.8 & 18.8 & 0.001 \\
\hline Higher & 28.7 & 38.5 & 9.7 & 0.001 \\
\hline \multicolumn{5}{|l|}{ Marital status } \\
\hline Currently married & 18.7 & 34.3 & 15.6 & 0.001 \\
\hline Widowed & 20.3 & 37.1 & 16.9 & 0.001 \\
\hline Others & 11.4 & 33.9 & 22.5 & 0.026 \\
\hline \multicolumn{5}{|l|}{ Working status } \\
\hline Working & 11.1 & 24.7 & 13.6 & 0.001 \\
\hline Retired & 23.7 & 34.6 & 10.9 & 0.001 \\
\hline \multirow[b]{2}{*}{ Household factors } & 23.3 & 42.2 & 18.9 & 0.001 \\
\hline & & & & \\
\hline \multicolumn{5}{|l|}{ MPCE quintile } \\
\hline Poorest & 12.9 & 25.3 & 12.4 & 0.001 \\
\hline Poorer & 16.5 & 30.0 & 13.5 & 0.001 \\
\hline Middle & 19.1 & 30.0 & 10.9 & 0.001 \\
\hline Richer & 21.2 & 43.3 & 22.1 & 0.001 \\
\hline Richest & 28.5 & 52.6 & 24.1 & 0.001 \\
\hline \multicolumn{5}{|l|}{ Religion } \\
\hline Hindu & 18.3 & 35.6 & 17.3 & 0.001 \\
\hline Muslim & 21.5 & 33.0 & 11.5 & 0.001 \\
\hline Christian & 25.4 & 47.9 & 22.5 & 0.001 \\
\hline Others & 26.2 & 31.2 & 5.1 & 0.008 \\
\hline \multicolumn{5}{|l|}{ Caste } \\
\hline Scheduled Caste & 17.6 & 28.6 & 11.1 & 0.001 \\
\hline Scheduled Tribe & 10.3 & 18.0 & 7.7 & 0.001 \\
\hline Other Backward Class & 19.9 & 36.3 & 16.4 & 0.001 \\
\hline Others & 23.0 & 37.7 & 14.7 & 0.001 \\
\hline \multicolumn{5}{|l|}{ Region } \\
\hline North & 21.3 & 32.1 & 10.8 & 0.001 \\
\hline Central & 11.3 & 22.0 & 10.7 & 0.002 \\
\hline East & 19.6 & 37.7 & 18.1 & 0.001 \\
\hline Northeast & 13.2 & 26.9 & 13.7 & 0.105 \\
\hline West & 22.3 & 35.1 & 12.8 & 0.002 \\
\hline South & 25.4 & 42.3 & 16.9 & 0.001 \\
\hline Total & 19.1 & 35.4 & 16.3 & 0.001 \\
\hline
\end{tabular}


Estimates from multivariate logistic regression decomposition estimates for urban-rural differentials in the prevalence of multimorbidity among older adults, 2017-18 (Table 3)

237 Table 3 shows the results of the multivariate decomposition analysis for multimorbidity among older adults by selected variables. The multivariate decomposition logistic regression analysis revealed that about $51 \%$ of the overall differences (urban-rural) in the prevalence of multimorbidity among older adults was due to compositional characteristics (endowments). In contrast, the remaining $49 \%$ was due to the difference in the effect of characteristics (Coefficient). Among the compositional change factors, obese/overweight, high-risk waist circumference, physical activity status, education, working status, and geographical region significantly affected the change contribution.

The urban-rural differences are explained mainly by geographical region, high-risk waist circumference, working status, obese/overweight, and education. The study found that the regional inequality in the prevalence of multimorbidity among older adults accounts for nearly $10 \%$ of the explained gap in both groups. Moreover, obese/overweight and high-risk waist circumference were found to narrow the difference in the prevalence of multimorbidity among older adults between urban and rural by $8 \%$ and $9.1 \%$, respectively. Finally, work status and education are found to reduce the urban-rural gap in the prevalence of multimorbidity among older adults by $8 \%$ and $6 \%$, respectively. 
Table-3. Multivariate logistic regression decomposition estimates for urban-rural differentials in multimorbidity among older adults in India, 2017-18

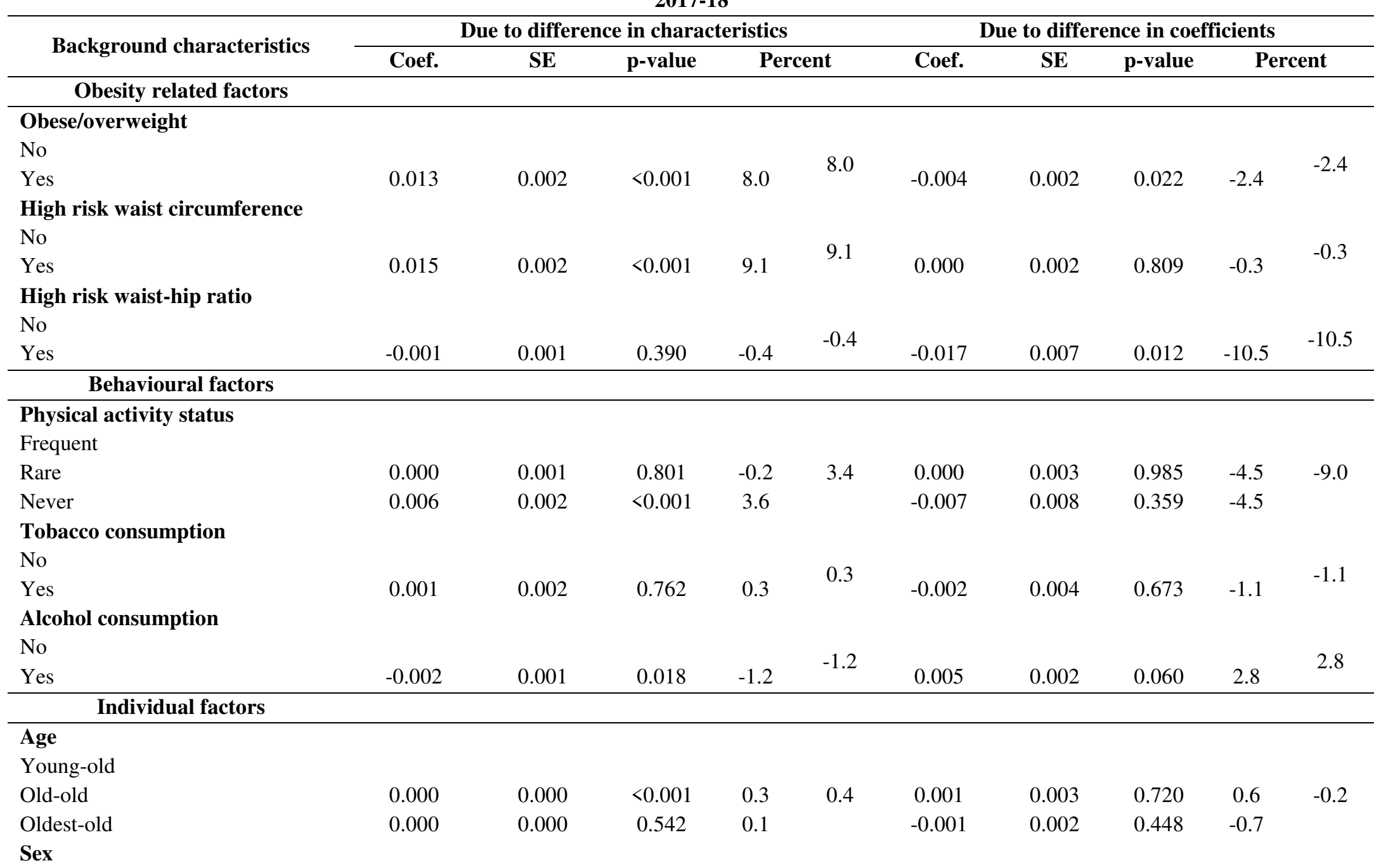


Male

Female

0.000

0.000

0.789

0.0

0.008

0.006

0.178

5.1

5.1

Not educated/primary not

completed

\begin{tabular}{|c|c|c|c|c|c|c|c|c|c|c|}
\hline Primary & 0.001 & 0.000 & 0.002 & 0.9 & \multirow[t]{3}{*}{6.1} & -0.002 & 0.001 & 0.233 & -1.0 & \multirow[t]{3}{*}{-3.9} \\
\hline Secondary & 0.004 & 0.001 & 0.005 & 2.4 & & -0.004 & 0.001 & 0.004 & -2.2 & \\
\hline Higher & 0.005 & 0.002 & 0.008 & 2.8 & & -0.001 & 0.001 & 0.048 & -0.7 & \\
\hline \multicolumn{11}{|l|}{ Marital status } \\
\hline \multicolumn{11}{|l|}{ Currently married } \\
\hline Widowed & 0.000 & 0.000 & 0.423 & 0.0 & \multirow[t]{2}{*}{-0.2} & -0.001 & 0.003 & 0.814 & -0.5 & \multirow[t]{2}{*}{-0.1} \\
\hline Others & 0.000 & 0.000 & 0.310 & -0.2 & & 0.001 & 0.001 & 0.319 & 0.3 & \\
\hline \multicolumn{11}{|l|}{ Working status } \\
\hline \multicolumn{11}{|l|}{ Working } \\
\hline Retired & 0.002 & 0.000 & $<0.001$ & 1.5 & \multirow[t]{2}{*}{8.1} & -0.011 & 0.005 & 0.023 & -6.5 & \multirow[t]{2}{*}{-10.1} \\
\hline Not working & 0.011 & 0.002 & $<0.001$ & 6.7 & & -0.006 & 0.003 & 0.072 & -3.6 & \\
\hline \multicolumn{11}{|c|}{ Household factors } \\
\hline \multicolumn{11}{|l|}{ MPCE quintile } \\
\hline \multicolumn{11}{|l|}{ Poorest } \\
\hline Poorer & 0.000 & 0.000 & 0.006 & 0.1 & \multirow{4}{*}{-0.3} & 0.000 & 0.003 & 0.963 & -0.1 & \multirow{4}{*}{-2.3} \\
\hline Middle & 0.000 & 0.000 & $<0.001$ & -0.2 & & -0.003 & 0.003 & 0.251 & -1.9 & \\
\hline Richer & 0.000 & 0.000 & $<0.001$ & -0.2 & & 0.001 & 0.003 & 0.808 & 0.4 & \\
\hline Richest & 0.000 & 0.000 & $<0.001$ & 0.0 & & -0.001 & 0.003 & 0.653 & -0.7 & \\
\hline \multicolumn{11}{|l|}{ Religion } \\
\hline \multicolumn{11}{|l|}{ Hindu } \\
\hline Muslim & 0.004 & 0.001 & $<0.001$ & 2.6 & \multirow{3}{*}{2.2} & 0.000 & 0.001 & 0.866 & -0.1 & \multirow{3}{*}{-2.6} \\
\hline Christian & -0.001 & 0.000 & 0.108 & -0.4 & & -0.002 & 0.002 & 0.333 & -1.1 & \\
\hline Others & 0.000 & 0.000 & 0.413 & 0.1 & & -0.002 & 0.001 & 0.021 & -1.4 & \\
\hline \multicolumn{11}{|l|}{ Caste } \\
\hline \multicolumn{11}{|l|}{ Scheduled Caste } \\
\hline Scheduled Tribe & 0.004 & 0.002 & 0.015 & 2.7 & \multirow{3}{*}{5.2} & 0.006 & 0.004 & 0.079 & 3.8 & \multirow{3}{*}{2.9} \\
\hline Other Backward Class & 0.000 & 0.000 & 0.681 & 0.0 & & -0.004 & 0.005 & 0.457 & -2.2 & \\
\hline Others & 0.004 & 0.002 & 0.093 & 2.4 & & 0.002 & 0.003 & 0.492 & 1.3 & \\
\hline Region & & & & & & & & & & \\
\hline
\end{tabular}

15 | $\mathrm{P}$ a g e 
North

\begin{tabular}{lcccccccccc} 
Central & 0.004 & 0.001 & 0.015 & 2.2 & & 0.004 & 0.003 & 0.115 & 2.6 & \\
East & -0.006 & 0.001 & 0.000 & -3.4 & 10.4 & 0.008 & 0.003 & 0.010 & 4.7 & 3.7 \\
Northeast & 0.003 & 0.001 & 0.003 & 1.9 & & 0.000 & 0.003 & 0.933 & 0.1 & \\
West & 0.004 & 0.001 & 0.003 & 2.1 & & -0.004 & 0.001 & 0.008 & -2.4 & \\
South & 0.012 & 0.002 & $<0.001$ & 7.6 & -0.002 & 0.003 & 0.392 & -1.3 & \\
Constant & & & & & & 0.119 & 0.023 & $<0.001$ & 72.6 & 72.6 \\
\hline Total & 0.083 & 0.004 & $<0.001$ & 50.9 & 0.080 & 0.006 & $<0.001$ & 49.1 \\
\hline
\end{tabular}




\section{Discussion:}

256 This study found that the overall prevalence of multimorbidity was lower among older adults 257 in rural areas (19.1\% vs. 35.4\%) than their urban counterparts. Several previous studies also noted a higher prevalence of multimorbidities among older adults in rural than older adults in urban [13]. The higher risk of multimorbidity in urban areas could be associated with increased prevalence of risk factors such as sedentary urban lifestyle, physical inactivity, and increase in energy and fat intake [26]. Urbanization also contributes to the increase in the prevalence of NCD risk factors [53]-[55]. Moreover, living in urban areas provides easy access to healthcare facilities, leading to higher health-seeking behaviour (Patel \& Chauhan, 2020), leading to prompt diagnosis of $\mathrm{NCD}$, raising the prevalence of multimorbidity in urban areas than in rural areas [56]. Furthermore, increasing nuclear family trends set up in urban areas could also be attributed to a higher risk of multimorbidity among older adults in urban [53].

The study found that obesity was an important factor among older adults experiencing multimorbidity. Results found that those who were obese were more likely to experience multimorbidity in rural and urban areas. Reducing urban-rural inequality in obesity-related factors would decline rural-urban inequalities in multimorbidity by almost 17 percent. Previous studies in developed as well as developing countries have unanimously agreed on a higher risk of multimorbidity among the obese population than in the non-obese population [27], [44], [57]-[63]. High waist-hip ratio and high-risk waist circumference were also associated with a high risk of multimorbidity among older adults, as noticed in previous studies [44]. Waist hip ratio and waist circumference were shown to be more sensitive among several anthropometric indices of obesity while screening for multimorbidity [44]. One widely followed hypothesis is

277 that obesity leads to a state of chronic inflammation due to the accumulation of adipose tissue,

278 further leading to stress response; all these events altogether lead to a rise in the incidence of morbidities such as cardiovascular diseases, diabetes, respiratory problems and other such 
chronic conditions [64], [65]. Moreover, obesity could be a consequence of the presence of multimorbidity, as shown in a prospective study by Nagel et al. (2008), who reported an increase in obesity as the number of morbidities increased [66]. The cross-sectional nature of data limits our understanding of causal inferences, and reverse causation cannot be ruled out in this study also. Obesity is a significant risk factor for chronic diseases, further leading to a higher risk of multimorbidity [61].

Physical inactivity was also noticed as an important risk factor for multimorbidity among older adults. Reducing inequality in physical activity among older adults would decline the urbanrural differential in multimorbidities among them, as shown in this study. Corroborating with previous findings [60], [67]-[69], this study noted an increased risk of multimorbidity among those who were never involved in physical activity than their counterparts in rural as well as in urban areas. However, a few studies failed to notice any association between multimorbidity and physical inactivity [59], [70]. On the other hand, being physically inactive could be associated with an increased risk of obesity which is well-linked to multimorbidity [59]. Furthermore, engaging in an active lifestyle has proven to be protective against several chronic diseases, such as coronary heart disease [71], diabetes [72], [73], and hypertension [73], [74], which could further be linked to the association between physical activity and multimorbidity.

Education status was another prominent factor infusing urban-rural inequality in the prevalence of multimorbidity among older adults. Results linked higher education to the risk for multimorbidity among older adults. Several previous studies have validated our finding on association between higher education and increased risk of multimorbidity in the Indian context [38]. However, quite a few studies conducted in different settings have noted a high risk of multimorbidity among uneducated older adults than educated older adults [75]-[77]. In addition, higher education is linked to better health literacy leading to increased consultations with health care providers, therefore increasing the probability of getting diagnosed with more 
chronic conditions [78], [79]. Another study in the Indian context also noted a positive correlation between higher education and the number of outpatient visits substantiating the claims of a higher risk of multimorbidity among educated people [38].

Confirming the evidence from previous studies [26], [31], this study noted that household wealth was associated with risk of multimorbidity where higher wealth among older adults was linked to a high risk of multimorbidity. This can be attributed to the fact that people from lower socio-economic status are less likely to seek health care and, therefore, less likely to have chronic diseases diagnosed [38]. In addition, higher income is linked to higher treatmentseeking affordability among older adults in India leading to a higher prevalence of multimorbidity [80]. In alignment with previous findings [31], [38], [78], [81], the findings in this study noted a higher prevalence of multimorbidity in female than in male older adults. Therefore, higher treatment-seeking among females at older ages could be attributed to a higher diagnosis of multimorbidity [80].

In agreement with previous studies [26], [82], [83], the prevalence of multimorbidity was higher among non-working groups than in a working group. Working older adults might be involved in some work-related physical activity and may not follow a sedentary lifestyle, which can explain low risk of multimorbidity [56]. The prevalence of multimorbidity was highest among older adults in the Southern region in the country and regions of India highly explained urban-rural inequality in the prevalence of multimorbidity. Previous studies agree with the finding and noticed a high risk of multimorbidity among older adults in residing in Southern part of the country [26], [84]. Kinra et al. (2010) believe that the risk factors associated with multimorbidity are widely prevalent among the South Indian population [84]. Compared to other parts of the country, South Indians have better socio-economic status (Rammohan \& Vu, 2018), further linked to the higher risk of multimorbidity. 


\section{Limitations and strengths of the study:}

330

The key strength of this study is the use of a recently released nationally representative sample that provides robust estimates of the study variables. However, there are some associated limitations too in this study. This is cross-sectional data and therefore limits the causal understanding. Respondents were asked whether they were diagnosed with any of the chronic diseases by a health professional. This could result in recall bias as some of the respondents might not be able to recollect particular chronic conditions. Furthermore, doctor diagnosis may be biased due to poor quality diagnosis in India [13]. Also, the reporting of multimorbidity was calculated by merging only nine available chronic conditions; there are many more chronic conditions for which data was not available, undermining the prevalence of multimorbidity. The available data only provides the prevalence and determinants related information; therefore limits our understanding of the severity of the diseases/multimorbidity.

\section{Conclusion:}

This study provides concrete evidence on the emerging rural-urban inequality in the prevalence of multimorbidity among older adults, highlighting the need for immediate interventions from health planners and policymakers. Specifically, our findings indicate a need for the growing burden of multimorbidity in urban areas to be considered within the framework of several factors predicting high urban-rural inequality in the prevalence of multimorbidity. Results found that controlling obesity-related factors and improving physical activity among older adults would decrease the urban-rural inequality in the prevalence of multimorbidity by almost 20 percent. Education was another significant predictor of urban-rural inequality in the prevalence of multimorbidity among older adults along with working status. Based on the findings, the study has some valuable suggestions. Although the direction of the relationship between several risk factors and multimorbidity could be debated, there is a need for public 
354 older adults, specifically in urban areas. There is a need to substantially increase the public 355 sector investment in healthcare to address the multimorbidity among older adults, more so in 356 urban areas, without compromising the needs of older adults in rural areas.

List of abbreviations:

360 LASI: Longitudinal Ageing Study in India

361 PSUs: Primary Sampling Units

362 CEB: Census Enumeration Block

363 MPCE: Monthly per Capita Expenditure

364 OBC: Other Backward Class

365 ST: Scheduled Tribe

366 SC: Scheduled Caste

367 NCD: Non-communicable Disease 
Ethics approval and consent to participate: The authors were not involved in data collection process and therefore they did not require any ethical approval or consent to participate. The LASI data is secondary in nature. The data is freely available on request and survey agencies that conducted the field survey for the data collection have collected a prior consent from the respondent. The ethical clearance was provided by Indian Council of Medical Research (ICMR), India. The survey agencies that collected data followed all the protocols. To maximize the cooperation of the sampled HHs and individuals, participants were provided with information brochures explaining the purpose of the survey, ways of protecting their privacy, and the safety of the health assessments as part of the ethics protocols. As per ethics protocols, consent forms were administered to each $\mathrm{HH}$ and age-eligible individual. In accordance with Human Subjects Protection, four consent forms were used in the LASI: Household Informed Consent, Individual Informed Consent, Consent for Blood Samples Collection for Storage and Future Use (DBS), and Proxy Consent. For each survey participant, the study protocol was described and the steps of each biomarker test were demonstrated by the trained health investigators. Participant's consent (signed/oral) was obtained for the interviews. Since, the survey obtained either signed or oral consent, it was feasible for each participant to provide his/her consent.

\section{Consent for publication: Not applicable}

Availability of data and materials: The datasets generated and/or analysed during the current study are available with the International Institute for Population Sciences, Mumbai, India repository and could be accessed from the following link: https://iipsindia.ac.in/sites/default/files/LASI_DataRequestForm_0.pdf. Those who wish to download the data have to follow the above link. This link leads to a data request form designed 
by International Institute for Population Sciences. After completing the form, it should be mailed to: datacenter@iips.net for further processing. After successfully sending the mail, individual will receive the data in a reasonable time.

Competing Interest: The authors declare that they have no competing interests.

Funding: Authors did not receive any funding to carry out this research.

Author's Contribution: The concept was drafted by SC. SS and PK contributed to the analysis design. SC advised on the paper and assisted in paper conceptualization. SC and RP contributed in the comprehensive writing of the article. All authors read and approved the final manuscript.

\section{Acknowledgements: Not applicable}

(1)

\section{References:}

[1] H. Wang et al., "Global age-sex-specific fertility, mortality, healthy life expectancy (HALE), and population estimates in 204 countries and territories, 1950-2019: a comprehensive demographic analysis for the Global Burden of Disease Study 2019," The Lancet, vol. 396, no. 10258, pp. 1160-1203, 2020.

[2] United Nations and Department of Economic and Social Affairs, "World population ageing, 2019 highlights,” NewYork, 2020.

[3] S. Chauhan and P. Arokiasamy, "India's demographic dividend: state-wise perspective," Journal of Social and Economic Development, vol. 20, no. 1, pp. 1-23, 2018. 
[4] R. Patel, S. Chauhan, D. Chaurasiya, S. Kumar, and B. Paswan, "Role and Impact of Social Capital on Health of Older Adult in India," Indian Journal of Social Research, vol. 60, no. 2, pp. 279-305, 2019.

[5] V. Mishra, "India's projected aged population (65+), projected life expectancy at birth and insecurities faced by aged population," Ageing International, pp. 1-13, 2019.

[6] National Institute on Ageing, "Why Population Aging Matters: A Global Perspective," National Institutes of Health, 07-6134, 2007. Accessed: May 31, 2021. [Online]. Available: https://journals.plos.org/plosone/article?id=10.1371/journal.pone.0237307

[7] J. Pearson-Stuttard, M. Ezzati, and E. W. Gregg, "Multimorbidity—a defining challenge for health systems," The Lancet Public Health, vol. 4, no. 12, pp. e599-e600, Dec. 2019, doi: 10.1016/S2468-2667(19)30222-1.

[8] S. Afshar, P. J. Roderick, P. Kowal, B. D. Dimitrov, and A. G. Hill, "Multimorbidity and the inequalities of global ageing: a cross-sectional study of 28 countries using the World Health Surveys," BMC Public Health, vol. 15, no. 1, p. 776, Aug. 2015, doi: $10.1186 / \mathrm{s} 12889-015-2008-7$.

[9] M. A. Khanam, P. K. Streatfield, Z. N. Kabir, C. Qiu, C. Cornelius, and A. Wahlin, "Prevalence and Patterns of Multimorbidity among Elderly People in Rural Bangladesh: A Cross-sectional Study," J Health Popul Nutr, vol. 29, no. 4, pp. 406-414, Aug. 2011.

[10] A. J. Koné Pefoyo et al., "The increasing burden and complexity of multimorbidity," BMC Public Health, vol. 15, no. 1, p. 415, Apr. 2015, doi: 10.1186/s12889-015-1733-2.

[11] R. Ofori-Asenso, K. L. Chin, A. J. Curtis, E. Zomer, S. Zoungas, and D. Liew, "Recent Patterns of Multimorbidity Among Older Adults in High-Income Countries," Population Health Management, vol. 22, no. 2, pp. 127-137, Aug. 2018, doi: 10.1089/pop.2018.0069. 
[12] P. Arokiasamy, Uttamacharya, and K. Jain, "Multi-Morbidity, Functional Limitations, and Self-Rated Health Among Older Adults in India: Cross-Sectional Analysis of LASI Pilot Survey, 2010," SAGE Open, vol. 5, no. 1, p. 2158244015571640, Mar. 2015, doi: $10.1177 / 2158244015571640$.

[13] S. Pati et al., "Non communicable disease multimorbidity and associated health care utilization and expenditures in India: cross-sectional study," BMC Health Services Research, vol. 14, no. 1, p. 451, Oct. 2014, doi: 10.1186/1472-6963-14-451.

[14] M. van den Akker, F. Buntinx, and J. A. Knottnerus, "Comorbidity or multimorbidity," European Journal of General Practice, vol. 2, no. 2, pp. 65-70, Jan. 1996, doi: $10.3109 / 13814789609162146$.

[15] E. Alonso-Morán, R. Nuño-Solinis, G. Onder, and G. Tonnara, "Multimorbidity in risk stratification tools to predict negative outcomes in adult population," European Journal of Internal Medicine, vol. 26, no. 3, pp. 182-189, Apr. 2015, doi: 10.1016/j.ejim.2015.02.010.

[16] R. Gijsen, N. Hoeymans, F. G. Schellevis, D. Ruwaard, W. A. Satariano, and G. A. M. van den Bos, "Causes and consequences of comorbidity: A review," Journal of Clinical Epidemiology, vol. 54, no. 7, pp. 661-674, Jul. 2001, doi: 10.1016/S08954356(00)00363-2.

[17] C. Salisbury, L. Johnson, S. Purdy, J. M. Valderas, and A. A. Montgomery, "Epidemiology and impact of multimorbidity in primary care: a retrospective cohort study," Br J Gen Pract, vol. 61, no. 582, pp. e12-e21, Jan. 2011, doi: 10.3399/bjgp11X548929.

[18] F. Castellana et al., "Physical Frailty, Multimorbidity, and All-Cause Mortality in an Older Population From Southern Italy: Results from the Salus in Apulia Study," Journal 
of the American Medical Directors Association, vol. 22, no. 3, pp. 598-605, Mar. 2021, doi: 10.1016/j.jamda.2020.12.026.

[19] L. Ge, C. W. Yap, and B. H. Heng, "Sex differences in associations between multimorbidity and physical function domains among community-dwelling adults in Singapore," PLOS ONE, vol. 13, no. 5, p. e0197443, May 2018, doi: 10.1371/journal.pone.0197443.

[20] U. Kadam, P. Croft, and North Staffordshire GP Consortium Group, "Clinical multimorbidity and physical function in older adults: a record and health status linkage study in general practice," Family Practice, vol. 24, no. 5, pp. 412-419, Oct. 2007, doi: 10.1093/fampra/cmm049.

[21] M. Y. Wei, M. U. Kabeto, K. M. Langa, and K. J. Mukamal, "Multimorbidity and Physical and Cognitive Function: Performance of a New Multimorbidity-Weighted Index," The Journals of Gerontology: Series A, vol. 73, no. 2, pp. 225-232, Jan. 2018, doi: 10.1093/gerona/glx114.

[22] M. Y. Wei, M. U. Kabeto, A. T. Galecki, and K. M. Langa, "Physical Functioning Decline and Mortality in Older Adults With Multimorbidity: Joint Modeling of Longitudinal and Survival Data," The Journals of Gerontology: Series A, vol. 74, no. 2, pp. 226-232, Jan. 2019, doi: 10.1093/gerona/gly038.

[23] M. Y. Wei, D. A. Levine, L. B. Zahodne, M. U. Kabeto, and K. M. Langa, "Multimorbidity and Cognitive Decline Over 14 Years in Older Americans," The Journals of Gerontology: Series A, vol. 75, no. 6, pp. 1206-1213, May 2020, doi: 10.1093/gerona/glz147.

[24] H.-W. Li et al., "Quality of Life among Community-Dwelling Middle-Aged and Older Adults: Function Matters More than Multimorbidity," Archives of Gerontology and Geriatrics, vol. 95, p. 104423, Jul. 2021, doi: 10.1016/j.archger.2021.104423. 
[25] M. E. Salive, “Multimorbidity in Older Adults," Epidemiol Rev, vol. 35, no. 1, pp. 75-83, 2013, doi: https://doi.org/10.1093/epirev/mxs009.

[26] A. Muksor, P. Dixit, and M. R. Varun, "Rural-Urban Differentials in NCD Multimorbidity in Adult Population in India: Prevalence and Cost of Care," Journal of Tropical Medicine and Health, vol. 10, no. 2, pp. 1-12, 2018.

[27] C. dos S. Costa et al., "Inequalities in multimorbidity among elderly: a population-based study in a city in Southern Brazil," Cad. Saúde Pública, vol. 34, p. e00040718, Nov. 2018, doi: 10.1590/0102-311x00040718.

[28] A. Marengoni, B. Winblad, A. Karp, and L. Fratiglioni, "Prevalence of Chronic Diseases and Multimorbidity Among the Elderly Population in Sweden," Am J Public Health, vol. 98, no. 7, pp. 1198-1200, Jul. 2008, doi: 10.2105/AJPH.2007.121137.

[29] H. Hien et al., "Prevalence and patterns of multimorbidity among the elderly in Burkina Faso: cross-sectional study," Tropical Medicine \& International Health, vol. 19, no. 11, pp. 1328-1333, 2014, doi: https://doi.org/10.1111/tmi.12377.

[30] R. Zhang, Y. Lu, L. Shi, S. Zhang, and F. Chang, "Prevalence and patterns of multimorbidity among the elderly in China: a cross-sectional study using national survey data," BMJ Open, vol. 9, no. 8, p. e024268, Aug. 2019, doi: 10.1136/bmjopen-2018024268.

[31] G. K. Mini and K. R. Thankappan, "Pattern, correlates and implications of noncommunicable disease multimorbidity among older adults in selected Indian states: a cross-sectional study," BMJ Open, vol. 7, no. 3, p. e013529, Mar. 2017, doi: 10.1136/bmjopen-2016-013529.

[32] P. Banjare and J. Pradhan, "Socio-Economic Inequalities in the Prevalence of MultiMorbidity among the Rural Elderly in Bargarh District of Odisha (India)," PLOS ONE, vol. 9, no. 6, p. e97832, Jun. 2014, doi: 10.1371/journal.pone.0097832. 
[33] A. Gupta, S. Girdhar, A. Chaudhary, J. S. Chawla, and P. Kaushal, "Patterns of multimorbidity among elderly in an urban area of North India," Journal of Evolution of Medical and Dental Sciences, vol. 5, no. 19, pp. 936-942, 2016.

[34] J. S. Kshatri, S. K. Palo, T. Bhoi, S. R. Barik, and S. Pati, "Prevalence and Patterns of Multimorbidity Among Rural Elderly: Findings of the AHSETS Study,” Front. Public Health, vol. 8, 2020, doi: 10.3389/fpubh.2020.582663.

[35] S. Pati, S. Swain, M. A. Hussain, S. Kadam, and C. Salisbury, "Prevalence, Correlates, and Outcomes of Multimorbidity Among Patients Attending Primary Care in Odisha, India," The Annals of Family Medicine, vol. 13, no. 5, pp. 446-450, Sep. 2015, doi: 10.1370/afm.1843.

[36] S. Pati, S. Swain, J. Metsemakers, J. A. Knottnerus, and M. van den Akker, "Pattern and severity of multimorbidity among patients attending primary care settings in Odisha, India," PLOS ONE, vol. 12, no. 9, p. e0183966, Sep. 2017, doi: 10.1371/journal.pone.0183966.

[37] V. Verma, N. Mishra, N. Mishra, and N. Mishra, “A Study on Multi-morbidity among Geriatric Group in a District of Northern India: A Cross Sectional Study,” International Journal of Medicine and Public Health, vol. 9, no. 4, pp. 137-140, 2019, doi: 10.5530/ijmedph.2019.4.29.

[38] S. Pati, S. Swain, J. A. Knottnerus, J. F. M. Metsemakers, and M. van den Akker, "Magnitude and determinants of multimorbidity and health care utilization among patients attending public versus private primary care: a cross-sectional study from Odisha, India," Int J Equity Health, vol. 19, no. 1, p. 57, Dec. 2020, doi: 10.1186/s12939-02001170-y. 
[39] International Institute for Population Sciences (IIPS), NPHCE, MoHFW, Harvard T. H. Chan School of Public Health (HSPH), and The university of Southern California (USC), “Longitudinal Ageing Study in India (LASI) Wave 1,” Mumbai, India, 2020.

[40] S. Srivastava, V. J. K. J, D. Dristhi, and T. Muhammad, "Interaction of physical activity on the related measures association of obesity- - with multimorbidity among older adults : a population- - based cross- - sectional study in India," BMJ Open, no. May, 2021, doi: 10.1136/bmjopen-2021-050245.

[41] S. P. McKenna, "Measuring patient-reported outcomes: moving beyond misplaced common sense to hard science," BMC Medicine, vol. 9, no. 1, p. 86, Jul. 2011, doi: $10.1186 / 1741-7015-9-86$.

[42] N. Garin et al., "Global Multimorbidity Patterns: A Cross-Sectional, Population-Based, Multi-Country Study," The Journals of Gerontology: Series A, vol. 71, no. 2, pp. 205214, Feb. 2016, doi: 10.1093/gerona/glv128.

[43] WHO, "Obesity and overweight: Fact sheet," 2016.

[44] J. Zhang, L. Xu, J. Li, L. Sun, and W. Qin, "Association between obesity-related anthropometric indices and multimorbidity among older adults in Shandong, China: a cross-sectional study," BMJ Open, vol. 10, no. 5, p. e036664, May 2020, doi: 10.1136/bmjopen-2019-036664.

[45] S. Srivastava and A. Gill, "Untreated morbidity and treatment-seeking behaviour among the elderly in India: Analysis based on National Sample Survey 2004 and 2014,” SSM Population Health, vol. 10, p. 100557, Apr. 2020, doi: 10.1016/j.ssmph.2020.100557.

[46] S. Srivastava and S. Kumar, "Does socio-economic inequality exist in micro-nutrients supplementation among children aged 6-59 months in India? Evidence from National Family Health Survey 2005-06 and 2015-16,” BMC Public Health, vol. 21, no. 1, p. 545, Mar. 2021, doi: 10.1186/s12889-021-10601-6. 
[47] S. Chauhan, T. V. Sekher, P. Kumar, S. Srivastava, and R. Patel, "Prevalence, determinants and socio-economic inequality of early marriage among men in India," Children and Youth Services Review, vol. 116, p. 105273, Sep. 2020, doi: 10.1016/j.childyouth.2020.105273.

[48] C. Fan, L. Wang, and L. Wei, "Comparing Two Tests for Two Rates," The American Statistician, vol. 71, no. 3, pp. 275-281, Jul. 2017, doi: 10.1080/00031305.2016.1246263.

[49] D. A. Powers, H. Yoshioka, and M.-S. Yun, "Mvdcmp: Multivariate Decomposition for Nonlinear Response Models,” The Stata Journal, vol. 11, no. 4, pp. 556-576, Dec. 2011, doi: $10.1177 / 1536867 X 1201100404$.

[50] S. A. Tiruneh, A. M. Lakew, S. T. Yigizaw, M. M. Sisay, and Z. T. Tessema, "Trends and determinants of home delivery in Ethiopia: further multivariate decomposition analysis of 2005-2016 Ethiopian Demographic Health Surveys,” BMJ Open, vol. 10, no. 9, p. e034786, Sep. 2020, doi: 10.1136/bmjopen-2019-034786.

[51] A. Debie, A. M. Lakew, K. S. Tamirat, G. Amare, and G. A. Tesema, "Complete vaccination service utilization inequalities among children aged 12-23 months in Ethiopia: a multivariate decomposition analyses," Int J Equity Health, vol. 19, no. 1, p. 65, Dec. 2020, doi: 10.1186/s12939-020-01166-8.

[52] L. StataCorp, "Stata statistical software (version release 14)," College Station, TX: Author, vol. 464, p. 465, 2015.

[53] D. Cantarero-Prieto, M. Pascual-Sáez, and C. Blázquez-Fernández, "Social isolation and multiple chronic diseases after age 50: A European macro-regional analysis," PLOS ONE, vol. 13, no. 10, p. e0205062, Oct. 2018, doi: 10.1371/journal.pone.0205062.

[54] P. S. Shetty, "Nutrition transition in India," Public Health Nutr, vol. 5, no. 1A, pp. 175182, Feb. 2002, doi: 10.1079/PHN2001291. 
[55] K. Yadav and A. Krishnan, "Changing patterns of diet, physical activity and obesity among urban, rural and slum populations in north India," Obesity Reviews, vol. 9, no. 5, pp. 400-408, 2008, doi: https://doi.org/10.1111/j.1467-789X.2008.00505.x.

[56] S. Srivastava, T. Anwar, R. Patel, and S. Chauhan, "Dynamics of chronic diseases in metro and non-metro regions of India: evidence from India Human Development Survey I and II," International Journal, vol. 6, no. 8, p. 322, 2020.

[57] C. B. Agborsangaya, D. Lau, M. Lahtinen, T. Cooke, and J. A. Johnson, "Multimorbidity prevalence and patterns across socioeconomic determinants: a cross-sectional survey," BMC Public Health, vol. 12, no. 1, p. 201, Mar. 2012, doi: 10.1186/1471-2458-12-201.

[58] S. Agrawal and P. K. Agrawal, “Association Between Body Mass index and Prevalence of Multimorbidity in Low-and Middle-income Countries: A Cross-Sectional Study," Int J Med Public Health, vol. 6, no. 2, pp. 73-83, Apr. 2016, doi: 10.5530/ijmedph.2016.2.5.

[59] V. de S. Santos Machado, A. L. R. Valadares, L. H. Costa-Paiva, M. J. Osis, M. H. Sousa, and A. M. Pinto-Neto, “Aging, obesity, and multimorbidity in women 50 years or older: a population-based study," Menopause, vol. 20, no. 8, pp. 818-824, Aug. 2013, doi: 10.1097/GME.0b013e31827fdd8c.

[60] V. de Souza Santos Machado, A. L. R. Valadares, L. S. da Costa-Paiva, S. S. Moraes, and A. M. Pinto-Neto, "Multimorbidity and associated factors in Brazilian women aged 40 to 65 years: a population-based study," Menopause, vol. 19, no. 5, pp. 569-575, May 2012, doi: 10.1097/gme.0b013e3182455963.

[61] C. Diederichs, K. Berger, and D. B. Bartels, "The Measurement of Multiple Chronic Diseases-A Systematic Review on Existing Multimorbidity Indices," The Journals of Gerontology: Series A, vol. 66A, no. 3, pp. 301-311, Mar. 2011, doi: 10.1093/gerona/glq208. 
[62] H.-J. Dong, M. Unosson, E. Wressle, and J. Marcusson, "Health Consequences Associated with Being Overweight or Obese: A Swedish Population-Based Study of 85Year-Olds," Journal of the American Geriatrics Society, vol. 60, no. 2, pp. 243-250, 2012, doi: https://doi.org/10.1111/j.1532-5415.2011.03827.x.

[63] D. Jovic, J. Marinkovic, and D. Vukovic, “Association between body mass index and prevalence of multimorbidity: a cross-sectional study," Public Health, vol. 139, pp. 103111, Oct. 2016, doi: 10.1016/j.puhe.2016.05.014.

[64] R. Cancello and K. Clément, "Review article: Is obesity an inflammatory illness? Role of low-grade inflammation and macrophage infiltration in human white adipose tissue," BJOG: An International Journal of Obstetrics \& Gynaecology, vol. 113, no. 10, pp. 11411147, 2006, doi: https://doi.org/10.1111/j.1471-0528.2006.01004.x.

[65] A. J. Guri and B. R. Josep, "Systemic Effects of White Adipose Tissue Dysregulation and Obesity-Related Inflammation,” Obesity, vol. 19, no. 4, pp. 689-700, 2011.

[66] G. Nagel, R. Peter, S. Braig, S. Hermann, S. Rohrmann, and J. Linseisen, “The impact of education on risk factors and the occurrence of multimorbidity in the EPIC-Heidelberg cohort," BMC Public Health, vol. 8, no. 1, p. 384, Nov. 2008, doi: 10.1186/1471-2458-8384.

[67] C. S. Autenrieth et al., "Physical activity is inversely associated with multimorbidity in elderly men: Results from the KORA-Age Augsburg Study," Preventive Medicine, vol. 57, no. 1, pp. 17-19, Jul. 2013, doi: 10.1016/j.ypmed.2013.02.014.

[68] N. N. Dhalwani et al., "Long terms trends of multimorbidity and association with physical activity in older English population," Int J Behav Nutr Phys Act, vol. 13, no. 1, p. 8, Jan. 2016, doi: 10.1186/s12966-016-0330-9. 
[69] M. S. Kaplan, J. T. Newsom, B. H. McFarland, and L. Lu, "Demographic and psychosocial correlates of physical activity in late life," American Journal of Preventive Medicine, vol. 21, no. 4, pp. 306-312, Nov. 2001, doi: 10.1016/S0749-3797(01)00364-6.

[70] C. Hudon, H. Soubhi, and M. Fortin, "Relationship between multimorbidity and physical activity: Secondary analysis from the Quebec health survey," BMC Public Health, vol. 8, no. 1, p. 304, Sep. 2008, doi: 10.1186/1471-2458-8-304.

[71] A. A. Hakim et al., "Effects of Walking on Coronary Heart Disease in Elderly Men," Circulation, vol. 100, no. 1, pp. 9-13, Jul. 1999, doi: 10.1161/01.CIR.100.1.9.

[72] G. Hu et al., "Occupational, commuting, and leisure-time physical activity in relation to risk for Type 2 diabetes in middle-aged Finnish men and women," Diabetologia, vol. 46, no. 3, pp. 322-329, Mar. 2003, doi: 10.1007/s00125-003-1031-x.

[73] U. Kapil et al., "Prevalence of hypertension, diabetes, and associated risk factors among geriatric population living in a high-altitude region of rural Uttarakhand, India," J Family Med Prim Care, vol. 7, no. 6, pp. 1527-1536, 2018, doi: 10.4103/jfmpc.jfmpc_108_18.

[74] M. Alam, G. Soni, K. Jain, S. Verma, and P. Panda, "Prevalence and determinants of hypertension in elderly population of Raipur city, Chhattisgarh," International Journal of Research in Medical Sciences, vol. 3, no. 3, pp. 568-573, Jan. 2015, doi: 10.5455/23206012.ijrms20150307.

[75] V. Johnson-Lawrence, A. Zajacova, and R. Sneed, "Education, race/ethnicity, and multimorbidity among adults aged 30-64 in the National Health Interview Survey," SSM - Population Health, vol. 3, pp. 366-372, Dec. 2017, doi: 10.1016/j.ssmph.2017.03.007.

[76] T. I. Pathirana and C. A. Jackson, "Socioeconomic status and multimorbidity: a systematic review and meta-analysis," Australian and New Zealand Journal of Public Health, vol. 42, no. 2, pp. 186-194, 2018, doi: https://doi.org/10.1111/1753-6405.12762. 
[77] M. L. Schiøtz, A. Stockmarr, D. Høst, C. Glümer, and A. Frølich, "Social disparities in the prevalence of multimorbidity - A register-based population study," BMC Public Health, vol. 17, no. 1, p. 422, May 2017, doi: 10.1186/s12889-017-4314-8.

[78] S. Pati et al., "Prevalence and outcomes of multimorbidity in South Asia: a systematic review," BMJ Open, vol. 5, no. 10, p. e007235, Oct. 2015, doi: 10.1136/bmjopen-2014007235.

[79] S. M. Smith, H. Soubhi, M. Fortin, C. Hudon, and T. O’Dowd, "Managing patients with multimorbidity: systematic review of interventions in primary care and community settings,” BMJ, vol. 345, p. e5205, Sep. 2012, doi: 10.1136/bmj.e5205.

[80] R. Patel and S. Chauhan, "Gender differential in health care utilisation in India," Clinical Epidemiology and Global Health, vol. 8, no. 2, pp. 526-530, 2020.

[81] N. Audinarayana, "Gender Perspectives of Multi-morbidity among Elderly and It's Determinants in an Urban Setting of Tamil Nadu.," Indian Journal of Gerontology, vol. 31, no. 1, pp. 119-136, 2017.

[82] O. Björklund, M. Söderlund, L. Nyström, and E. Häggström, “Unemployment and Health: Experiences Narrated by Young Finnish Men,” Am J Mens Health, vol. 9, no. 1, pp. 7685, Jan. 2015, doi: 10.1177/1557988314536725.

[83] L. Picco et al., "Economic burden of multimorbidity among older adults: impact on healthcare and societal costs," BMC Health Serv Res, vol. 16, May 2016, doi: $10.1186 / \mathrm{s} 12913-016-1421-7$.

[84] S. Kinra et al., "Sociodemographic patterning of non-communicable disease risk factors in rural India: a cross sectional study,” BMJ, vol. 341, no. sep27 1, pp. c4974-c4974, Sep. 2010, doi: 10.1136/bmj.c4974. 